Interactive comment on "Inversion of multi-angular polarimetric measurements over open and coastal ocean waters: a joint retrieval algorithm for aerosol and water leaving radiance properties” by Meng Gao et al.

\title{
Meng Gao et al.
}

meng.gao@nasa.gov

Received and published: 6 June 2019

Please find our response in the attached file.

Please also note the supplement to this comment:

https://www.atmos-meas-tech-discuss.net/amt-2019-67/amt-2019-67-AC2- 